\title{
Transcriptome response comparison between vector and non-vector aphids after feeding on virus-infected wheat plants
}

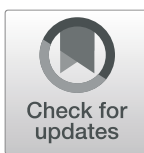

Dandan Li ${ }^{1}$, Chi Zhang ${ }^{1}$, Zeqian Tong ${ }^{1}$, Dan Su${ }^{1}$, Gaisheng Zhang², Shize Zhang ${ }^{1}$, Huiyan Zhao ${ }^{1}$ and Zuqing $\mathrm{Hu}^{1 *}$ (i)

\begin{abstract}
Background: Plant viruses maintain intricate interactions with their vector and non-vector insects and can impact the fitness of insects. However, the details of their molecular and cellular mechanisms have not been studied well. We compared the transcriptome-level responses in vector and non-vector aphids (Schizaphis graminum and Rhopalosiphum padi, respectively) after feeding on wheat plants with viral infections (Barley Yellow Dwarf Virus (BYDV) and Wheat dwarf virus (WDV), respectively). We conducted differentially expressed gene (DEG) annotation analyses and observed DEGs related to immune pathway, growth, development, and reproduction. And we conducted cloning and bioinformatic analyses of the key DEG involved in immune.

Results: For all differentially expressed gene analyses, the numbers of DEGs related to immune, growth, development, reproduction and cuticle were higher in vector aphids than in non-vector aphids. STAT5B (signal transducer and activator of transcription 5B), which is involved in the JAK-STAT pathway, was upregulated in R. padi exposed to WDV. The cloning and bioinformatic results indicated that the RpSTAT5B sequence contains a $2082 \mathrm{bp}$ ORF encoding 693 amino acids. The protein molecular weight is $79.1 \mathrm{kD}$ and pl is 8.13. Analysis indicated that RPSTAT5B is a non-transmembrane protein and a non-secreted protein. Homology and evolutionary analysis indicated that RPSTAT5B was closely related to $R$. maidis.

(Continued on next page)
\end{abstract}

\footnotetext{
* Correspondence: huzuqing@nwsuaf.edu.cn

'State Key Laboratory of Crop Stress Biology in Arid Areas, College of Plant Protection, Northwest A\&F University, Yangling, China

Full list of author information is available at the end of the article
}

(c) The Author(s). 2020 Open Access This article is licensed under a Creative Commons Attribution 4.0 International License, which permits use, sharing, adaptation, distribution and reproduction in any medium or format, as long as you give appropriate credit to the original author(s) and the source, provide a link to the Creative Commons licence, and indicate if changes were made. The images or other third party material in this article are included in the article's Creative Commons licence, unless indicated otherwise in a credit line to the material. If material is not included in the article's Creative Commons licence and your intended use is not permitted by statutory regulation or exceeds the permitted use, you will need to obtain permission directly from the copyright holder. To view a copy of this licence, visit http://creativecommons.org/licenses/by/4.0/. The Creative Commons Public Domain Dedication waiver (http://creativecommons.org/publicdomain/zero/1.0/) applies to the data made available in this article, unless otherwise stated in a credit line to the data. 
(Continued from previous page)

Conclusions: Unigene expression analysis showed that the total number of differentially expressed genes (DEGs) in the vector aphids was higher than that in the non-vector aphids. Functional enrichment analysis showed that the DEGs related to immunity, growth and reproduction in vector aphids were higher than those in non-vector aphids, and the differentially expressed genes related to immune were up-regulated. This study provides a basis for the evaluation of the response mechanisms of vector/non-vector insects to plant viruses.

Keywords: BYDV, WDV, Vector, Non-vector, Transcriptome response, Gene clone

\section{Background}

Schizaphis graminum and Rhopalosiphum padi are serious pests of cereal crops, particularly wheat that may cause harm to plants by feeding on them and by transmitting the Barley yellow dwarf virus (BYDV) (Luteoviridae: Luteovirus) in a persistent and nonproliferative manner [1-4]. That causes one of the most economically important viral diseases of cereal plants [5, 6]. In China, there were 4 isolated strains be identified as GPV, GAV, PAV and RMV and the BYDV-GAV is the major isolate [7]. Wheat dwarf virus (WDV) (Geminiviridae: Mastrevirus) is another serious virus of wheat in China that causes significant losses and is mainly transmitted by the leafhopper Psammotettix alienus (Dahlbom) in a persistent and non-proliferative manner $[8,9]$. S. graminum is a vector of BYDV-GAV and is a non-vector of WDV, while $R$. padi is a non-vector of both BYDV-GAV and WDV.

The aphids (S. graminum and $R$. padi) and viruses (BYDV-GAV and WDV) used in our study are important insect pests and viral pathogens that often occur together on the same host plant in agro-ecosystems. The plant-arthropod-pathogen interactions are complex, and some studies have shown that plant viruses can produce favorable or unfavorable effects on vector/or non-vector insects $[10,11]$. Exploring the effect of viruses on aphids can provide a better understanding of these three-way interactions and improve integrated pest management.

Previous studies showed that plant virus infection of its host plant could result in either beneficial or adverse effects on its vector via direct feeding or other indirect ways [12, 13]. Transcriptional induction or repression is an important mechanism for insects to regulate their innate immune responses [14]. There are a few previous reports that have studied the global transcription profiles of insect vectors fed on virus-infected plants. Brault [15] conducted the first large-scale analysis of aphid gene regulation following virus acquisition. Southern rice black-streaked dwarf virus (SRBSDV) infection activated the immune regulatory systems of the white-backed planthopper (WBPH) [16]. Transcriptome analysis of the thrips response to Tomato spotted wilt virus (TSWV) infection showed that the diversity of the innate immune-related transcripts in response to viral infection was most pronounced in the P1 stage [17].
Reproduction, embryo development and growth were associated with upregulated contigs in virus-exposed Frankliniella fusca adults [18].

Compared with vectors, there are fewer studies on nonvectors. Although less studied, there is some evidence that plant viruses have an impact on non-vectors. The nymph survival rate was decreased and the longevity of female adults was shortened, while egg hatchability increased in response to non-vector brown planthoppers feeding on SRBSDV-infected plants [19]. In contrast, rice plants infected by $R$ ice black-streaked dwarf virus (RBSDV) improved the ecological fitness of the brown planthopper [20]. In addition, TSWV infection reduced the fecundity and longevity of B. tabaci and increased the developmental time of Bemisia tabaci [21]. Additionally, feeding on plants inoculated with TSWV enhanced the developmental and oviposition rates of spider mites [22].

Pathogenic infections may affect the physiology of the host insect and even cause death [23]. In the process of long-term evolution, insects have formed defense mechanisms to achieve a dynamic balance between viruses and insects. Insects rely on their immune system to resist the invasion of pathogens, which is not conducive to the replication and transmission of the virus. One of the long-term goals of studying virus-insect interactions is to elucidate the molecular mechanism by which viruses affect the innate immune system of insects to avoid damage from the immune defense response. Therefore, understanding the insect's immune system is key to solving this problem. Immune-related signaling pathways that have been studied in insects include the RNAi, Toll, JAK/STAT, phagocytosis, apoptosis, proteolysis and JNK pathways [18, 24, 25].

Because the persistent plant viruses cannot break through the midgut barrier or salivary gland barrier of non-vector insects, they cannot be transmitted by the non-vector insects [26]. We previously have found that plant virus (e.g., BYDV-GAV and WDV) can be detected in non-vector aphids (e.g., R. padi) (unpublished data). Previous studies aslo have shown that plant viruses can improve the fitness of non-vector insects (as well as vectors) [20-23]. We speculate that plant viruses in nonvector aphids can also affect their biochemical response. At present, the molecular and cytological mechanism of plant viruses to the vector and non-vector insects is not 
Table 1 Summary statistics for S. graminum and R. padi transcriptome assembly

\begin{tabular}{lll}
\hline Statistics & S. graminum & R. padi \\
\hline Total number of transcripts & 160,522 & 142,240 \\
Total number of unigenes & 72,092 & 68,996 \\
Unigenes length > 1 kb & 13,758 & 12,588 \\
Mean length of unigenes & 833.11 & 805.47 \\
N50 unigene length & 1481 & 1497 \\
\hline
\end{tabular}

clear, so BYDV-GAV and WDV were used as the test viruses, $R$. padi and $S$. graminum were used as the test insects to compare the transcriptome changes of the vector and non-vector insects to the plant viruses, so as to find out the differences between the plant viruses affecting the gene expression of the vector and non-vector insects. This study will lay the foundation for the molecular mechanism of plant viruses to improve the fitness of non-mediator insects.

\section{Results}

\section{Sequence assembly and annotation}

To explore the transcriptome response to viral infection by vector and non-vector aphids, we performed RNASeq analysis on adult $S$. graminum and $R$. padi exposed to BYDV-infected, WDV-infected and uninfected wheat plants. The $S$. graminum and $R$. padi cDNA libraries were sequenced, which generated 72,092 and 68,996 unigenes, respectively (Table 1 ). The N50 sizes were $1481 \mathrm{~kb}$ and $1497 \mathrm{~kb}$, respectively. The Q30 of each transcriptome library was above 85.74 and $85.62 \%$ for $S$. graminum and $R$. padi, respectively.

$\mathrm{Nr}$ (non-redundant protein sequence database) homologous species distribution revealed that $71.64 \%$ of S. graminum sequences matched with Acyrthosiphon pisum (Fig. 1 a), and $67.81 \%$ of $R$. padi sequences matched with $A$. pisum (Fig. 1 b). For the Gene ontology assignment, 7263 and 8164 unigenes in S. graminum and $R$. padi could be annotated. For S. graminum, 6200 unigenes were associated with biological process, 3080 with cellular component, and 6344 with molecular function (Fig. S1 A). In R. padi, 7104 unigenes were associated with biological process, 3597 with cellular component, and 7173 with molecular function (Fig. S1 B). These sequences have been submitted to the NCBI Sequence Read Archive (SRA), and the accession number is PRJNA490258.

DEGs (Differentially expressed genes) in S. graminum and $R$. padi, as the vector/non-vector, in response to feeding on virus-infected wheat plants

For S. graminum fed on BYDV-infected wheat, 1525 DEGs were identified, with 693 upregulated and 832

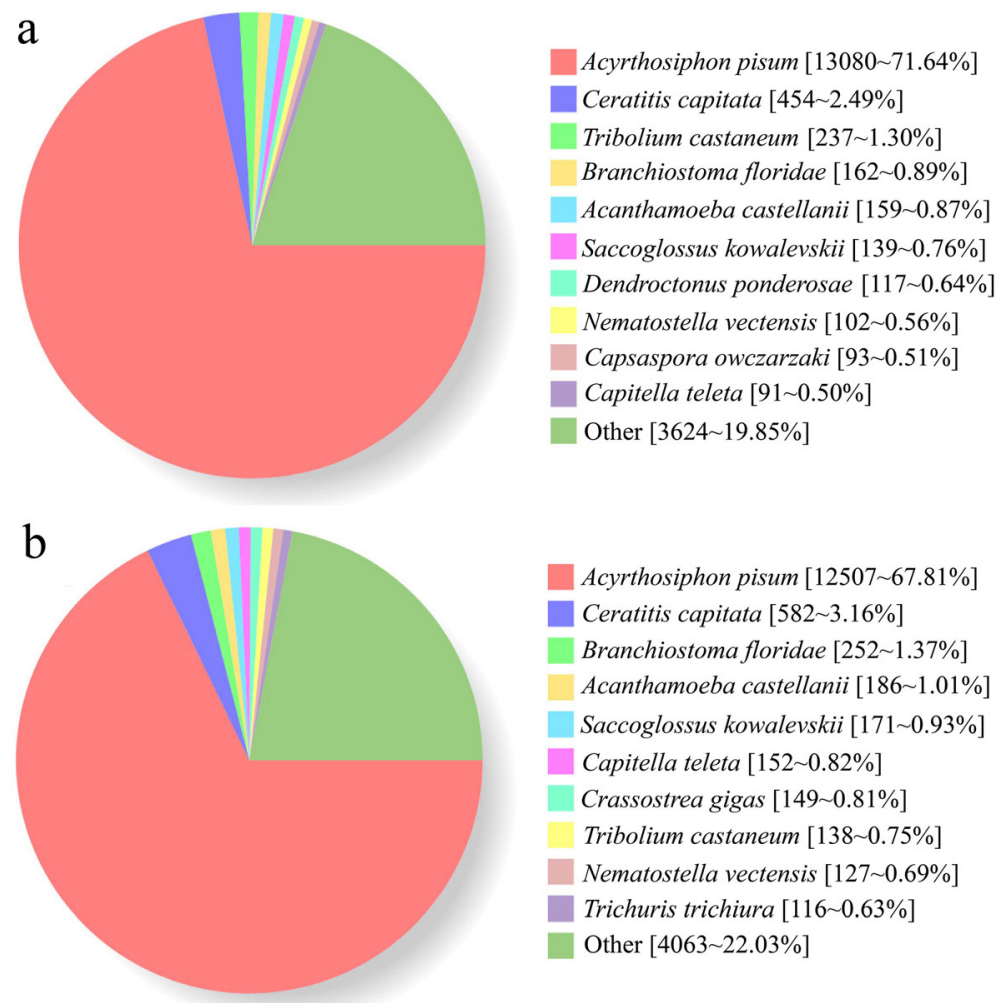

Fig. $1 \mathrm{Nr}$ homologous species distribution of S. graminum a and R. padi $\mathbf{b}$ 

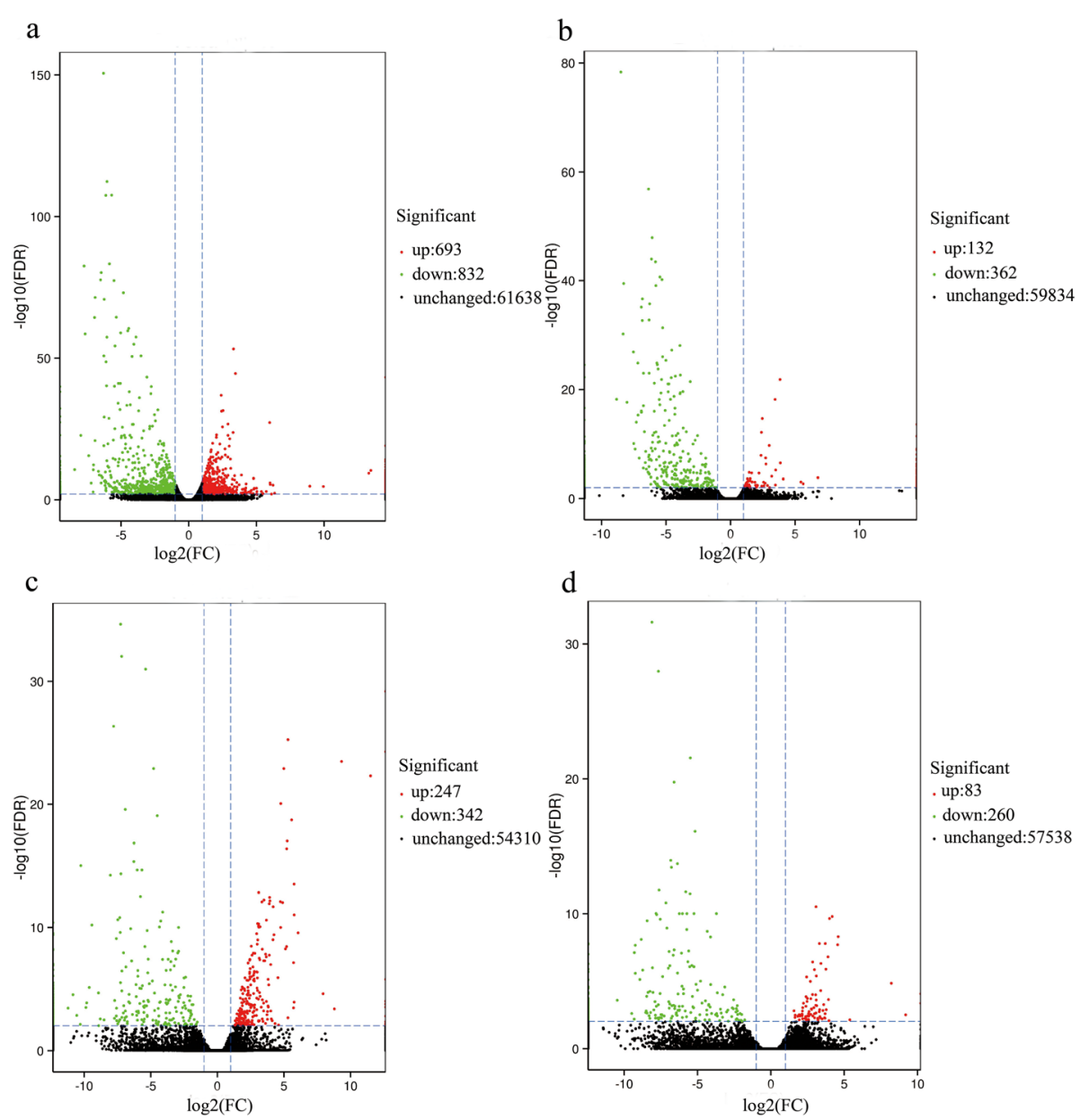

Fig. 2 Volcano Plot of DEGs in S. graminum fed on wheat infected with BYDV a, S. graminum fed on wheat infected with WDV b, R. padi fed on wheat infected with BYDV $\mathbf{c}$ and S. graminum fed on wheat infected with BYDV d

downregulated. There were fewer DEGs in the S. graminum fed on WDV-infected wheat (494), and the majority were downregulated (73.28\%). There were 589 DEGs in R. padi exposed to BYDV-infected wheat, with 247 upregulated and 342 downregulated. A total of 343 DEGs were identified in $R$. padi exposed to WDV-infected wheat, with $75.8 \%$ downregulated. The change ratios of most DEGs were between $2^{-5}$ and $2^{5}$ (Fig. 2). Gene ontology (GO) and Kyoto Encyclopedia of Genes and Genomes (KEGG) enrichment analyses were conducted for all DEGs.

\section{Distribution and enrichment of DEGs in vector and non- vector aphids into gene ontologies (GOs)}

Gene ontology (GO) analysis of all the DEGs in $S$. graminum and $R$. padi was conducted to classify the sequences into the biological process, molecular function and cellular component categories (Figs. S2, S3, S4, S5). The most enriched category in both vector and non- vector aphids was metabolic process (Figs. S2, S3, S4, S5). Among all comparisons, the differentially expressed genes contained a high proportion of genes involved in development, metabolism, reproduction and growth, and the number in vector aphids was higher (29 DEGs in SgBYDV) than that in non-vector aphids $(13,13$, and 3 DEGs in Sg-WDV, Rp-BYDV, and Rp-WDV, respectively) (Fig. 3 and Table S5). In addition, genes associated with the cuticle (structural constituent of the cuticle and structural constituent of the chitin-based cuticle) were also differentially expressed, and there were 16 DEGs in the vector treatment (Sg-BYDV), while there were fewer in the non-vector treatments (with 2 in Sg-WDV, 5 in Rp-BYDV, and 2 in Rp-WDV). In Sg-BYDV, there were 15 DEGs associated with the cuticle, and the majority of them were downregulated (14 downregulated) (Fig. 3 and Table 2). Several genes involved in the cytoskeleton were also differentially expressed, with 6, 1, and 2 related DEGs in Sg-BYDV, Sg-WDV, and Rp-BYDV, 


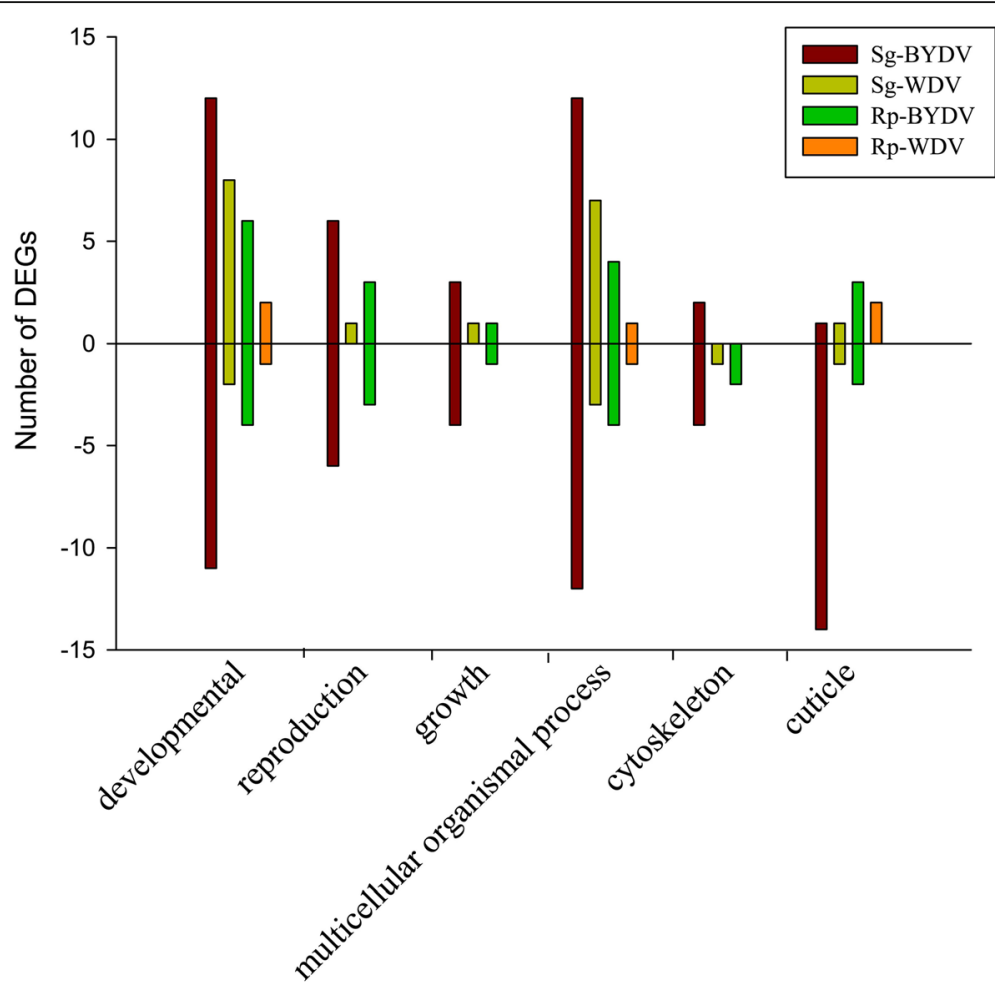

Fig. 3 Number of differentially expressed genes (DEGs) involved in the development, reproduction, growth, multicellular organismal process, cytoskeleton and cuticle of vector (Sg-BYDV) and non-vector (Sg-WDV, Rp-BYDV, and Rp-WDV) aphids

respectively (Fig. 3 and Table 3). The results of GO enrichment analysis showed that the number of categories of DEGs enriched in vector aphids was higher than that in non-vector aphids (Figs. S2, S3, S4, S5). The Clusters of Orthologous Groups of proteins (COG) enrichment analysis showed a similar pattern in that the number of categories in the vector aphids was greater than that in the non-vector aphids (Figs. S6, S7, S8, S9).

\section{KEGG pathways analysis}

To further understand the metabolic pathways that contained differentially expressed genes, KEGG significant enrichment analysis was performed on the differentially expressed genes between virus-treated vector and non-vector aphids. Among all of the DEGs, there were 287, 74, 91 and 27 DEGs that were assigned to KEGG pathways in Sg-BYDV, Sg-WDV, Rp-BYDV and RpWDV, respectively (Fig. S10, S11, S12, S13). The DEGs of the richest and shared pathways were associated with metabolism, including translation and fatty acid and carboxylic acid metabolic pathways. Genes involved in energy production pathways may be important for immune defense responses [27]. In the KEGG pathway analyses, we also identified DEGs involved in immune pathways.
Immune-related DEGs of vector and non-vector aphids feeding on virus-infected wheat

Feeding on virus-infected plants resulted in DEGs related to the innate immunity pathway being upregulated. The DEGs related to immunity included several members of the pathway of the lysosomes, the JAK-STAT signaling pathway, antigen processing and presentation, ubiquitin mediated proteolysis, and the peroxisome (Table 4). For the DEG analyses, we identified 12 DEGs involved in immune pathways in the vector aphids (SgBYDV), the majority of which were upregulated (11 DEGs). For the non-vector aphids, there were fewer DEGs related to immunity, and only one DEG involved in immunity was identified in each of the Sg-WDV, RpBYDV, and Rp-WDV conditions (Table 4).

\section{RT-qPCR}

RT-qPCR was used to confirm the expression of 14 selected DEGs of $S$. graminum and $R$. padi. These genes were selected because we were interested in their function, since they were involved in immunity, development, growth and reproduction. Based on the transcriptome data, ten unigenes, namely, Sg35675 (Synaphin protein), Sg36590 (Immunoglobulin domain), Sg40066 (Glycosyl hydrolases family), Sg43786 (plexin A3-like), Sg48920 (Immunoglobulin domain), Sg51592 
Table 2 DEGs involved in the cuticle in vector (Sg-BYDV) and non-vector (Sg-WDV, Rp-BYDV, Rp-WDV and Rp-WDV) aphids

\begin{tabular}{|c|c|c|c|c|}
\hline & Gene ID & Annotation & $\log 2 \mathrm{FC}$ & FDR \\
\hline \multirow[t]{15}{*}{ Sg-BYDV } & Sg39301 & structural constituent of cuticle & -1.646 & $8.07 E-05$ \\
\hline & Sg27246 & structural constituent of cuticle & -1.028 & $5.62 \mathrm{E}-07$ \\
\hline & Sg19143 & structural constituent of cuticle & -1.872 & $6.79 \mathrm{E}-08$ \\
\hline & Sg56253 & structural constituent of cuticle & -2.454 & 7.80E-14 \\
\hline & Sg17654 & structural constituent of cuticle & 2.147 & $1.02 \mathrm{E}-06$ \\
\hline & Sg27360 & structural constituent of cuticle & -1.646 & $1.08 \mathrm{E}-15$ \\
\hline & Sg56455 & structural constituent of cuticle & -1.722 & 0.001659 \\
\hline & Sg56015 & structural constituent of cuticle & -1.178 & 0.000655 \\
\hline & Sg35648 & structural constituent of cuticle & -1.328 & $1.59 \mathrm{E}-08$ \\
\hline & Sg53861 & structural constituent of cuticle & -1.740 & 0.00481 \\
\hline & Sg47817 & structural constituent of cuticle & -2.061 & 0.002456 \\
\hline & Sg36013 & structural constituent of cuticle & -1.347 & 0.001048 \\
\hline & Sg54274 & structural constituent of cuticle & -1.190 & $7.25 \mathrm{E}-12$ \\
\hline & Sg55542 & structural constituent of cuticle & -1.864 & 0.000179 \\
\hline & Sg30508 & structural constituent of chitin-based cuticle & -1.155 & 0.001031 \\
\hline \multirow[t]{2}{*}{ Sg-WDV } & Sg17654 & structural constituent of cuticle & 2.458 & 2.12E-15 \\
\hline & Sg54274 & structural constituent of cuticle & -1.892 & 0.00097 \\
\hline \multirow[t]{5}{*}{ Rp-BYDV } & Rp23024 & structural constituent of cuticle & 2.045 & 0.000696 \\
\hline & Rp23495 & structural constituent of cuticle & -2.608 & 0.000335 \\
\hline & Rp37328 & structural constituent of cuticle & -2.086 & 9.10E-05 \\
\hline & Rp18153 & structural constituent of cuticle & 4.732 & $8.00 \mathrm{E}-13$ \\
\hline & Rp22931 & structural constituent of chitin-based cuticle & 3.899 & 1.19E-12 \\
\hline \multirow[t]{2}{*}{ Rp-WDV } & Rp48839 & structural constituent of cuticle & 2.603 & 0.001872 \\
\hline & Rp18153 & structural constituent of cuticle & 3.776 & 0.001354 \\
\hline
\end{tabular}

Annotation: determined by BLAST

(transcriptional regulator CRZ2-like), Sg53134 (Cadherin domain), Sg56027 (Repeat in HS1/Cortactin), Sg30601 (AAA domain), Sg35800 (PDZ domain) were highly upor down-regulated in virus-exposed S. graminum. The remaining six unigenes, Rp22910 (apolipophorin-3-like precursor), Rp22931 (cuticular protein 68 precursor), Rp46740 (lysosomal alpha-mannosidase-like), Rp49092

Table 3 DEGs involved in cytoskeleton

\begin{tabular}{lllll}
\hline & Gene ID & Annotation & log2FC & FDR \\
\hline Sg-BYDV & Sg53134 & Cytoskeleton & 1.098 & $3.88 \mathrm{E}-08$ \\
& Sg55484 & Cytoskeleton & -2.175 & $3.45 \mathrm{E}-05$ \\
& Sg32025 & Cytoskeleton & Inf & $8.62 \mathrm{E}-08$ \\
& Sg56027 & Cytoskeleton & -1.346 & 0.000376 \\
& Sg49676 & Cytoskeleton & -1.527 & 0.008734 \\
& Sg55690 & cytoskeleton & -1.879 & $5.80 \mathrm{E}-18$ \\
Sg-WDV & Sg55690 & Cytoskeleton & -2.033 & $7.56 \mathrm{E}-07$ \\
Rp-BYDV & Rp29892 & Cytoskeleton & -4.719 & $2.19 \mathrm{E}-05$ \\
& Rp50802 & Cytoskeleton & -3.857 & 0.000136 \\
\hline
\end{tabular}

(STAT protein), were highly expressed in virus-exposed R. padi. The results of RT-qPCR showed that all 14 selected genes showed the same expression patterns (upregulated or downregulated) as the RNA-Seq analyses (Fig. 4).

\section{Cloning and characterization of STAT5B in R. padi}

For the immunity related genes analysis, STAT5B (signal transducer and activator of transcription $5 \mathrm{~B}$ ) was the only related gene that was upregulated in $R$. padi fed on WDV infected wheat. STAT5B is a key gene involved in the JAK-STAT pathway, which is important for the innate immune response of insects. Based on the sequence of the transcriptome, we cloned STAT5B from $R$. padi (designated as RpSTAT5B). The cloned product was validated using RT-PCR and sequencing. The sequencing results of the RPSTAT5B individual isolated colonies confirmed a single transcript identical to that found in the transcriptome sequencing. We have submitted the sequence of STAT5B to the NCBI GenBank database (accession number MK931299). The cloned product of 
Table 4 Immune-related DEGs expressed in virus-infected S. graminum and R. padi

\begin{tabular}{|c|c|c|c|c|c|}
\hline Treatment & Gene ID & Gene Name & Pathways & $\log 2 \mathrm{FC}$ & FDR \\
\hline \multirow[t]{12}{*}{ Sg-BYDV } & Sg55104 & PIAS1 & JAK-STAT signaling pathway & 1.305 & 0.00022237 \\
\hline & Sg50416 & UBE2D & Ubiquitin mediated proteolysis & 5.042 & 0.001199371 \\
\hline & Sg49574 & BIRC2_3 & Ubiquitin mediated proteolysis & 1.164 & 4.42E-09 \\
\hline & Sg55104 & PIAS1 & Ubiquitin mediated proteolysis & 1.304 & 0.00022237 \\
\hline & Sg42560 & $\mathrm{HAO}$ & Peroxisome & 1.287 & $6.39 \mathrm{E}-08$ \\
\hline & Sg43235 & cathepsin & Lysosome & 3.728 & 4.94E-06 \\
\hline & Sg45052 & cathepsin & Lysosome & 4.559 & 0.00263105 \\
\hline & Sg47282 & cathepsin & Lysosome & 2.494 & $2.06 \mathrm{E}-05$ \\
\hline & Sg56271 & cathepsin & Lysosome & -2.725 & $1.22 \mathrm{E}-05$ \\
\hline & Sg53565 & Legumain & Lysosome & 2.621 & 4.84E-08 \\
\hline & Sg40066 & LAMAN & Lysosome & 1.223 & 2.49E-07 \\
\hline & Sg55760 & NPC2 & Lysosome & 1.436 & 0.009359831 \\
\hline Sg-WDV & Sg40066 & LAMAN & Lysosome & 1.312 & 2.49E-07 \\
\hline Rp-BYDV & Rp46740 & LAMAN & Lysosome & 1.514 & 0.00928585 \\
\hline Rp-WDV & Rp49092 & STAT5B & JAK-STAT signaling pathway & 2.138 & 0.00295669 \\
\hline
\end{tabular}

FC (fold change): calculated by RPKM

$F D R$ false discovery rate

RpSTAT5B is $2364 \mathrm{bp}$, and it has a complete open reading frame of $2082 \mathrm{bp}$ encoding 693 amino acids, with a molecular weight of $83.2 \mathrm{kDa}$ and a theoretical isoelectric point of 8.31 .

Multiple protein sequence alignment of RpSTAT5B with six STAT5B proteins from other insects was conducted. Structural analysis showed that the RpSTAT5B protein has the typical structural features of the STAT5B family (Fig. 5). Phylogenetic analysis indicated that the amino acid sequence of the
RpSTAT5B protein showed high identity to that of the corresponding proteins from other aphids of Homoptera, particularly Rhopalosiphum maidis (Fig. 6). Both the RT-qPCR and transcriptome results showed that RpSTAT5B was upregulated in $R$. padi fed on WDV infected wheat (Fig. 4), suggesting that RpSTAT5B is critical to the response to feeding on infected wheat plants. However, the mechanism of RpSTAT5B in aphid immune defense remains to be further studied.

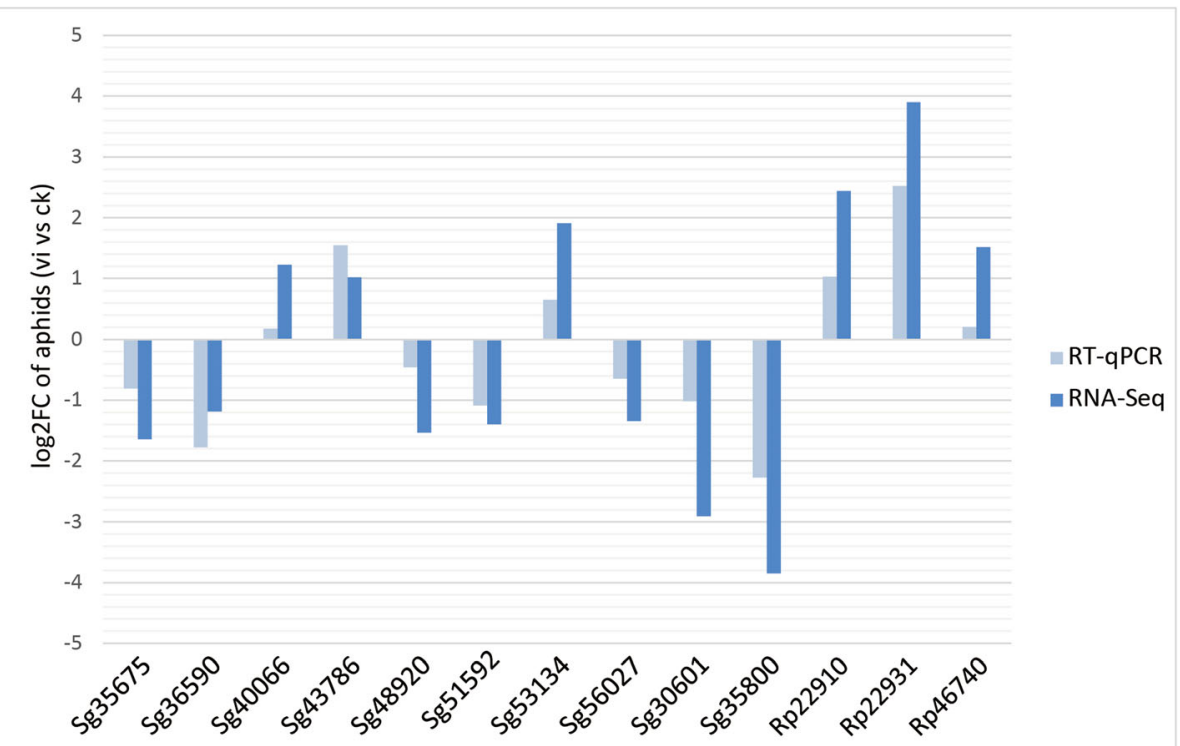

Fig. 4 Quantitative reverse transcription-polymerase chain reaction (RT-qPCR) validation of selected genes differentially regulated in S. graminum and R. padi fed on virus-infected wheat (vi) compared with a virus-free control (ck) S. avenae 


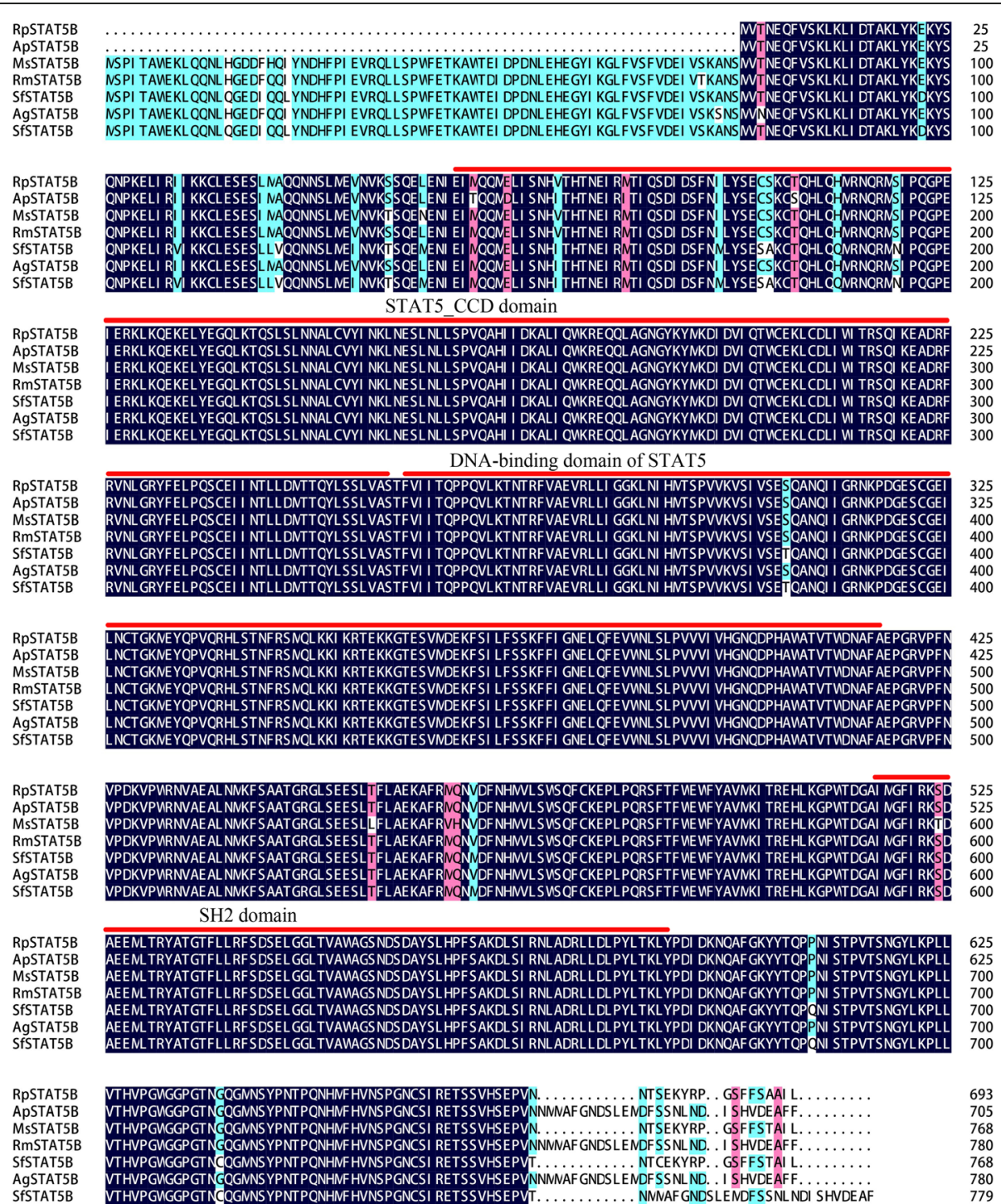

Fig. 5 RpSTAT5B amino acid sequence alignment with other STAT5Bs from other insects. ApSTAT5B: Acyrthosiphon pisum, XP_008188159.1; MsSTAT5B: Melanaphis sacchari, XP_025209095.1; RmSTAT5B: Rhopalosiphum maidis, XP_026814403.1; SfSTAT5B: Sipha flava, XP_025407855.1; AgSTAT5B: Aphis gossypii, XP_027841453.1; SfSTAT5B: S. flava, XP_025407854.1

\section{Discussion}

Our study investigated the effects of plant viruses on vector and non-vector insects at the transcriptional level. The number of DEGs was greater in the vector aphids (SgBYDV with 1525) than in the non-vector aphids (SgWDV, Rp-BYDV, and Rp-WDV with 494, 589 and 343, respectively). For all DEGs, the analysis showed that many of the DEGs were involved in development, growth and reproduction. The numbers of genes related to these processes were higher in the vectors (Sg-BYDV) than in the non-vectors (Sg-WDV, Rp-BYDV, and Rp-WDV).

For the GO analyses of all DEGs, the genes associated with the cuticles were mostly downregulated.
Particularly in the vector aphids (Sg-BYDV), there were 16 genes associated with cuticles that were differentially expressed, among which 15 genes were downregulated. Moreover, fewer related DEGs were identified in the non-vectors, i.e., two DEGs in Sg-WDV, five DEGs in Rp-BYDV, and two DEGs in Rp-WDV. The cuticle is of great importance for the survival of insects, since it is the articulated exoskeleton that protects the body against the invasion of pathogens $[28,29]$. The cuticle and its primary biopolymer components, cuticular proteins and chitin, of insects are periodically turnedover and new cuticle is secreted by the insect epidermis during ecdysis (molting) to accommodate the rapid 


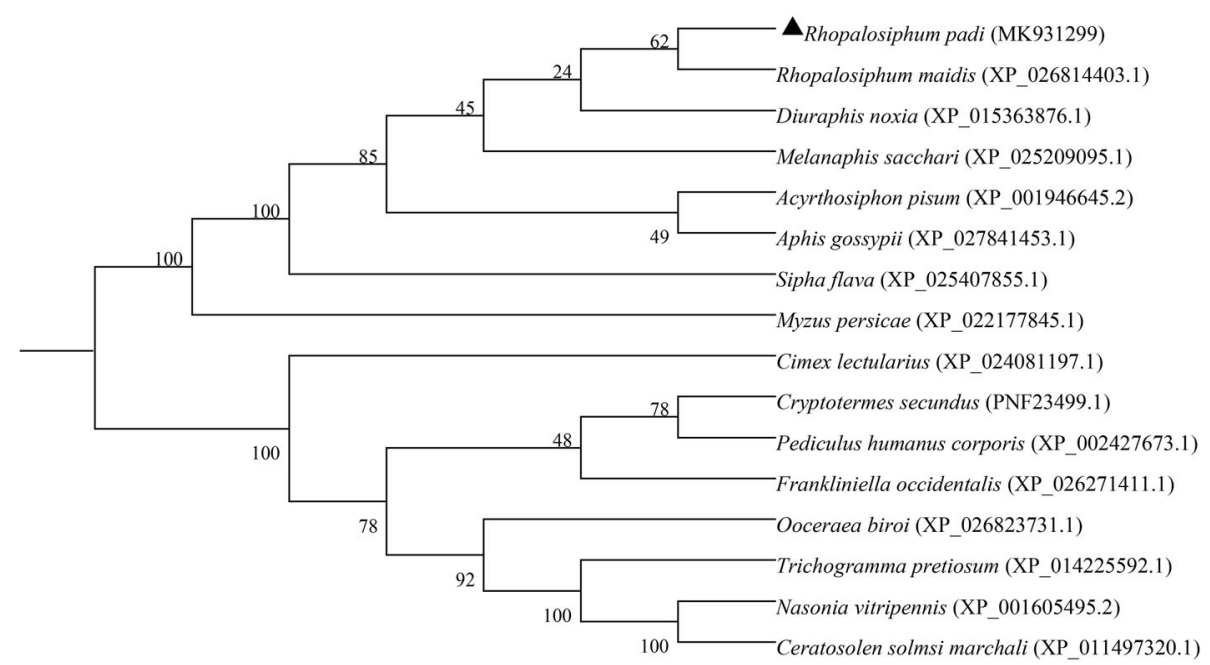

Fig. 6 Phylogenetic relationship of RPSTAT5B with other insect STAT5Bs. Sequences were aligned using Clustal Omega and the neighbor-joining tree was constructed using MEGA6.0. Sequences used in the analysis are listed in Table S4

growth and expansion of the body, and it is thought that temporally and spatially-dynamic epidermal expression of diverse cuticular and endocuticle proteins occurs to support the structure of different hard and soft cuticles of insect body parts during development [30]. The down-regulation of genes associated with the cuticles in aphids under wheat virus infection may signify a delay in molting or turnover of cuticle-associated proteins. One study reported a similar downregulation of six of seven cuticular proteins $(\mathrm{CP})$ transcript sequences of Plodia interpunctella (Indian meal moth) $24 \mathrm{~h}$ after exposure to the baculovirus Plodia interpunctella Granulosis Virus (PiGV) [31]. The authors hypothesized that infection suppressed activities of cuticular proteins embedded in the peritrophic matrix, a structural barrier to pathogen attack [32, 33]. However, they alternatively offered the possibility that the pathogenic virus may also negatively affect molting.

Insects rely on their immune system to fight against pathogens [34]. After feeding on virus-infected wheat plants, the DEGs related to immunity in S. graminum and $R$. padi were upregulated, including the JAKSTAT signaling pathway, the lysosome, antigen processing and presentation, ubiquitin mediated proteolysis and the peroxisome. As shown in our results, the number of DEGs related to immunity in $S$. graminum exposed to BYDV was higher than that in $S$. graminum exposed to WDV and in $R$. padi exposed to BYDV and WDV. These results suggest that feeding on virus-infected plants has a greater effect on the immune system of vector insects than that of non-vector insects. The DEGs involved in the cytoskeleton were also differentially expressed, which may be related to the immune response [35]. There have been previous studies showing that viruses can interact with and reorganize host cytoskeleton components for intercellular trafficking and infection processes [18, 36-38]. In addition, the cytoskeleton is also commonly involved in the intracellular transport of viruses [39-42].

There were 3 DEGs upregulated in Sg-BYDV that were related to ubiquitin mediated proteolysis, which is important for insect defenses against pathogens [43]. In this pathway, we identified that UBE2D (ubiquitin-conjugating enzyme E2 D), BIRC2_3 (baculoviral IAP repeat-containing protein 2/3) and PIAS1 (E3 SUMOprotein ligase PIAS1) were upregulated. The E2 enzyme is the ubiquitin carrier protein or ubiquitin-conjugating enzyme that can transfer ubiquitin from E1 to the substrate [44]. Inhibitors of apoptosis proteins (IAPs), also known as baculovirus IAP repeat (BIR)-containing proteins (BIRCs), generally display anti-apoptotic properties when overexpressed [45]. PIAS1 has been recognized as a small ubiquitin-like modifier (SUMO) ligase [46].

Lysosome pathway is important in humoral immune response. We identified CTSB (cathepsin B), LGMN (legumain), LAMAN (lysosomal alpha-mannosidase), NPC2 (Niemann-Pick C2 protein) associated with lysosome were up-regulated in S. graminum exposed to BYDV; LAMAN was up-regulated in S. graminum and $R$. padi exposed to WDV. Cathepsins are proteases involved in protein degradation, apoptosis, and signaling, and they regulate viral infection and transmission [4749]. In the green peach aphid, a lysosomal cathepsin B is upregulated following acquisition of the circulative- 
transmitted virus, Potato leafroll virus (PLRV), and together, the protein and virus colocalize at the cell membranes of midgut cells [49].

The JAK-STAT signaling pathway is important for innate immunity and antiviral responses in insects [5053]. This pathway consists of the ligand unpaired (UPD), the receptor Domeless, JAK, STAT, protein inhibitor of activated STAT (PIAS), suppressor of cytokine signaling (SOCS), and signal transducing adaptor molecule (STAM) $[43,54,55]$. We found that PIAS1 (Sg55104) was up-regulated in the Sg-BYDV aphids; this gene encodes E3 SUMO-protein ligase PIAS1. A previous study has shown that PIAS1 is a specific inhibitor of Stat1mediated gene activation [56]. In addition, STAT was up-regulated in the Rp-WDV aphids. JAK activation occurs upon ligand-mediated receptor multimerization, and the activated JAKs subsequently phosphorylate additional targets, including both the receptors and the major substrates, STATs. Phosphorylated STATs enter the nucleus by a mechanism that is dependent on importin a-5 (also called nucleoprotein interactor 1 ) and the Ran nuclear import pathway. Once in the nucleus, dimerized STATs bind specific regulatory sequences to activate or repress transcription of target genes (Fig. S14) [57].

STAT5B was the only related gene that was differentially expressed in $R$. padi fed on WDV infected wheat. RpSTAT5B possesses the SH2 (Src-homology Domain), STAT5_CCD (Coiled-coiled Domain), and the STAT_ DBD (STAT_bind) conserved domains, which are the

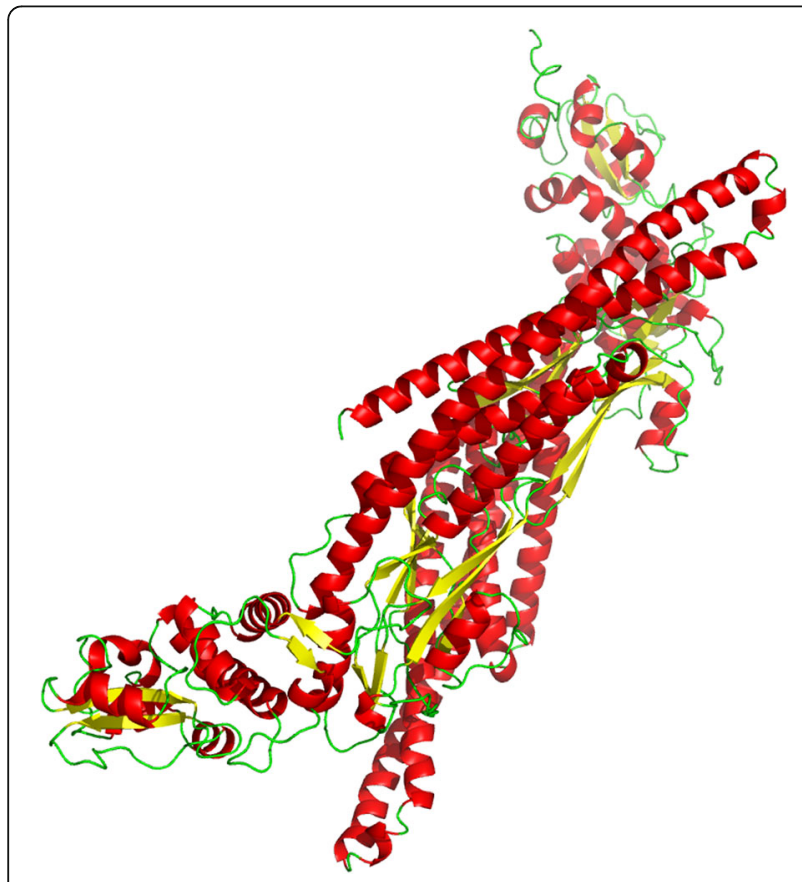

Fig. 7 Predicted protein structure of RpSTAT5B characteristic conserved domains of STAT5 (Fig. 5) [5862]. For prediction of its three-dimensional structure, the SWISS-MODEL template library (SMTL version 2019-06-27, PDB release 2019-06-21) was searched with BLAST and HHBlits for evolutionary related structures matching RpSTAT5B. The predicted three-dimensional structure of RpSTAT5B is shown in Fig. 7, and its identity with the template (SMTL ID: 1ylu.1.A) is $45.47 \%$. Overall, the identification of RpSTAT5B, and its increased expression in $R$. padi fed on WDV infected wheat, suggests it may fulfill a specific physiological role. Future studies are needed to understand the function of RpSTAT5B in R. padi fed on WDV infected wheat.

Insect pests and viral diseases are important factors affecting wheat yield. In this study, we analyzed the response of vector/non-vector aphids to wheat virus at the transcriptional level. Among all DEGs analyzed, we identified several genes associated with immunity, growth, development, reproduction and the cuticle of aphids. The results revealed that the number of DEGs and the functions related to the DEGs were both higher in vector aphids than that in non-vector aphids. This may imply that wheat viruses have a larger impact on vector than non-vector aphids. Exposure to the virus activated the immunity response of the aphids, particularly vector aphids. These results will provide a reference for investigation of new methods to improve the efficiency of pest control, including prokaryotic expression and gene silencing.

\section{Methods}

Insect rearing and plant infection by the viruses

Aphids from each of the species $S$. graminum and $R$. padi was collected from Yangpingguan $\left(34.85^{\circ} \mathrm{N}\right.$, $105.63^{\circ} \mathrm{E}$ ), Shaanxi Province, and they were maintained on wheat seedlings in growth chambers kept at $20 \pm$ $1{ }^{\circ} \mathrm{C}, 65 \% \pm 5 \%$ relative humidity and a photoperiod of 16: $8 \mathrm{~h}$ (L: D). Aphids used in the study were parthenogenetic descendants from a single isolated female. BYDV (isolate BYDV-GAV) and WDV were collected from Yangling $\left(34.28^{\circ} \mathrm{N}, 108.22^{\circ} \mathrm{E}\right)$ and Hancheng $\left(35.47^{\circ} \mathrm{N}\right.$, $\left.110.45^{\circ} \mathrm{E}\right)$, Shaanxi Province, China, from winter wheat plants. The viruses were identified using RT-PCR and agarose gel electrophoresis using the methods briefly described below.

We isolated total RNA from the wheat using TRIzol reagent (TaKaRa, Japan) following the manufacturers' instructions to test whether wheat was infected by BYDV. The cDNA was synthesized using PrimeScript RT Master Mix (TaKaRa, Japan). We isolated total gDNA from the wheat using DNAsecure Plant Kit (TIANGEN, China) following the manufacturers' instructions to test whether wheat was infected by WDV. Then PCR was performed; the primers used for the virus identification 
are shown in Table S1. The PCRs consisted of the following: $6.5 \mu \mathrm{l}$ of Reaction Mix (TIANGEN, China), $1 \mu \mathrm{l}$ of each forward and reverse primer, $1 \mu \mathrm{l}$ of cDNA/gDNA and $4.5 \mu \mathrm{l}$ of ddH2O. The cycling conditions were $94{ }^{\circ} \mathrm{C}$ for $3 \mathrm{~min}$; 35 cycles of $94{ }^{\circ} \mathrm{C}$ for $30 \mathrm{~s}, 55^{\circ} \mathrm{C}$ for $30 \mathrm{~s}$, and $72{ }^{\circ} \mathrm{C}$ for $1 \mathrm{~min}$; and finally, $72^{\circ} \mathrm{C}$ for $5 \mathrm{~min}$. Then, agarose gel electrophoresis was performed, and we sequenced the PCR products to confirm that the wheat was infected by BYDV or WDV. The detailed methods of the BYDV-infected and WDV-infected plant treatments, as transmitted by the leafhopper and S. graminum, respectively, have been previously described as follows [63]. Wheat plants at the second leaf stage were first covered with transparent, plastic, tube-shaped cages $(30 \mathrm{~cm}$ in height, $13.5 \mathrm{~cm}$ in diameter, and with a mesh screen cover on the top), and then 5 late instar nymphs of the vector were introduced into the cage and allowed to feed on the leaves. All the nymphs were removed after 5 days, and the treated plants were maintained under the growth chamber described as above.

\section{Feeding assays and RNA isolation}

The young first instar nymphs of $S$. graminum and $R$. padi were fed on BYDV-infected, WDV-infected, and healthy wheat plants to achieve six experimental treatments: the vector treatment was defined as S. graminum fed on BYDV-infected wheat (Sg-BYDV); the non-vector treatment was defined as $S$. graminum fed on WDVinfected wheat and $R$. padi fed on BYDV-GAV-infected, WDV-infected wheat (Sg-WDV, Rp-BYDV, Rp-WDV); and the control treatments were $S$. graminum and $R$. padi fed on healthy wheat seedlings (Sg-ck, Rp-ck).

Three biological replications of each treatment were conducted and each replicate contained 20 individual aphids. For each treatment-replicate, they were maintained in a growth chamber under the same environmental conditions as described above. We collected 20 adult aphids into a $1.5 \mathrm{ml}$ tube, and they were immediately flash frozen in liquid nitrogen and stored at $-80^{\circ} \mathrm{C}$. Total RNA was extracted from each sample using TRIzol reagent (TaKaRa, Japan) following the manufacturers' instructions. RNA degradation and contamination were monitored on $1 \%$ agarose gels. RNA purity was checked using the NanoPhotometer ${ }^{\circ}$ spectrophotometer (IMPLEN, CA, USA). RNA concentration was measured using a Qubit ${ }^{\circ}$ RNA Assay Kit in a Qubit ${ }^{\circ} 2.0$ Fluorometer (Life Technologies, CA, USA). RNA integrity was assessed using the RNA Nano 6000 Assay Kit of the Agilent Bioanalyzer 2100 system (Agilent Technologies, CA, USA).

\section{Transcriptome sequencing and analysis}

A total amount of $3 \mu \mathrm{g}$ of RNA per sample was used as input material for the RNA sample preparations. Sequencing libraries were generated using the NEBNext ${ }^{\circ}$
Ultra $^{\text {ta }}$ RNA Library Prep Kit for Illumina ${ }^{\bullet}$ (NEB, USA) following the manufacturer's recommendations. Briefly, mRNA was purified from the total RNA using poly-T oligo-attached magnetic beads. Fragmentation was carried out, and the first and second strands were synthesized. The purified and adaptor-ligated cDNA was subjected to PCR amplification. Finally, the PCR products were purified (AMPure XP system), and the library quality was assessed on the Agilent Bioanalyzer 2100 system.

The clustering of the index-coded samples was performed on a cBot Cluster Generation System using a TruSeq PE Cluster Kit v3-cBot-HS (Illumina) according to the manufacturer's instructions. After cluster generation, the library preparations were sequenced on an Illumina Hiseq 2000 platform and paired-end reads were generated. Clean data were obtained by removing reads containing adapters, reads containing poly- $\mathrm{N}$ and lowquality reads. At the same time, the Q20, Q30, GCcontent and sequence duplication level of the clean data were calculated. All of the downstream analyses were based on clean data with high quality. Transcriptome assembly was accomplished using Trinity (r20131110) with min_kmer_cov set to 2 by default and all other parameters set to default [64].

Differential expression analysis of the two groups was performed using the DESeq R package (1.10.1). DESeq provides statistical routines for determining differential expression of digital gene expression data using a model based on the negative binomial distribution. The resulting $P$ values were adjusted using the Benjamini and Hochberg's approach for controlling the false discovery rate. Genes with an adjusted $P$-value $<0.05$ found by DESeq were considered differentially expressed.

Gene ontology (GO) enrichment analysis of the differentially expressed genes (DEGs) was implemented by the topGO $\mathrm{R}$ packages based on the Kolmogorov-Smirnov test. We used KOBAS software to test the statistical enrichment of the differentially expressed genes in the KEGG pathways. Genes with similar expression patterns are usually functionally related. Cluster 3.0 software was used to analyze differentially expressed genes by hierarchical clustering with Euclidean distance as the distance matrix. The clustering results were displayed by Java Treeview.

\section{RT-qPCR validation}

To validate differential expression in response to the viruses, 13 transcript sequences were selected in $S$. graminum and $R$. padi and then compared with the expression levels between the virus-exposed and nonvirus-exposed aphids. Actin was used as an internal reference gene to normalize the expression level. The primers were designed using Primer Premier 5.0 
software and are shown in Table S2. The total RNA extraction and cDNA synthesis methods were performed as described above. Total RNA was isolated from three biological replicates, and each targeted gene included three technical replicates.

The reactions of real-time RT-qPCR were performed in $25 \mu \mathrm{l}$ volumes using TB Green Premix Ex Taq (TaKaRa, Japan) with $12.5 \mu \mathrm{l}$ of TB Green Premix Ex Taq II, $1 \mu \mathrm{l}$ of each forward and reverse primer $(10 \mu \mathrm{M})$, $0.5 \mu \mathrm{l}$ of ROX Reference Dye II, $2 \mu \mathrm{l}$ of cDNA and $8 \mu \mathrm{l}$ of nuclease free water. The cycling parameters were as follows: $95^{\circ} \mathrm{C}$ for $30 \mathrm{~s}$ and 40 cycles of $95^{\circ} \mathrm{C}$ for $5 \mathrm{~s}$ and $60^{\circ} \mathrm{C}$ for $30 \mathrm{~s}$. A standard curve experiment was set up by performing a dilution series with $5^{-1}$ dilution times and 5 dilution points to evaluate the PCR efficiency (E). The Q-PCR was performed on a QuantStudio 3 RealTime PCR System (Applied Biosystems), and QuantStudio $^{\text {tx }}$ Design and Analysis Software was used to analyze the PCR assays. The relative quantitative data analysis was performed using the $2^{-\Delta \Delta \mathrm{ct}}$ method.

\section{Cloning and characterization of the STAT5B}

STAT5B (signal transducer and activator of transcription $5 B)$ was the only relevant gene that was differentially expressed in $R$. padi fed on WDV infected wheat. To understand the mechanism of STAT5B in the insect immune defense response, we designed primers using Primer Premier 5.0 to clone STAT5B based on the sequence found in the transcriptome (Table S3). PCR analyses were conducted on a PCR Amplifier (purchased from Eppendorf, Yangling, China) using Tks Gflex ${ }^{\text {Tu }}$ DNA Polymerase (purchased from TaKaRa, Yangling, China). Cloned products were validated by RT-PCR and sequencing. Multiple sequence alignments were performed using Clustal W and DNAMAN. The phylogenetic tree was generated in Mega 6 using the Neighbor-Joining method. All sequences used in the analysis are listed in Table S4. The protein structure model was predicted using WISS-MODEL (https:// swissmodel.expasy.org/) and visualized in Pymol (v1.3r1).

\section{Supplementary information}

Supplementary information accompanies this paper at https://doi.org/10. 1186/s12864-020-07057-0.

Additional file 1 Figure S1. GO enrichment of (A) S. graminum, (B) $R$. padi. Figure S2. GO enrichment analysis of DEGs of $S$. graminum fed on BYDV-infected wheat. Figure S3. GO enrichment analysis of DEGs of $S$. graminum fed on WDV-infected wheat. Figure S4. GO enrichment analysis of DEGs of $R$. padi fed on BYDV-infected wheat. Figure S5. GO enrichment analysis of DEGs of $R$. padi fed on WDV-infected wheat. Figure S6. COG enrichment analysis of DEGs of S. graminum fed on BYDVinfected wheat. Figure S7. COG enrichment analysis of DEGs of S. graminum fed on WDV-infected wheat. Figure S8. COG enrichment analysis of DEGs of R. padi fed on BYDV-infected wheat. Figure S9. COG enrichment analysis of DEGs of $R$. padi fed on WDV-infected wheat. Figure S10 KEGG pathway analysis of DEGs of $S$. graminum fed on BYDV-infected wheat. Figure S11. KEGG pathway analysis of DEGs of S. graminum fed on WDV-infected wheat. Figure S12. KEGG pathway analysis of DEGs of $R$. padi fed on BYDV-infected wheat. Figure S13. KEGG pathway analysis of DEGs of $R$. padi fed on WDV-infected wheat. Figure S14 JAK/STAT signaling pathway.

Additional file $\mathbf{2}$ Table S1. Primers of the genes used for RT-PCR. Table S2. Primers of the genes used for RT-qPCR. Table S3. Primers of STAT5B. Table S4 Sequences used in the STAT5B analysis. Table S5. DEGs related to development, reproduction and growth of Sg-BYDV, Sg-WDV, RpBYDV, and Rp-WDV.

\section{Abbreviations}

BYDV: Barley yellow dwarf virus; WDV: Wheat dwarf virus; S. graminum: Schizaphis graminum; R. padi: Rhopalosiphum padi

DEGs: Differentially expressed genes; Sg-BYDV: Schizaphis graminum feeding on wheat infected by BYDV; Sg-WDV: Schizaphis graminum feeding on wheat infected by WDV; Rp-BYDV: Rhopalosiphum padi feeding on wheat infected by BYDV; Rp-WDV: Rhopalosiphum padi feeding on wheat infected by WDV; STAT5B: Signal transducer and activator of transcription 5B; TSWV: Tomato spotted wilt virus; SRBSDV: Southern rice black-streaked dwarf virus; WBPH: White backed planthopper; RBSDV: Rice black streaked dwarf virus; RTqPCR: Quantitative real-time PCR; GO: Gene ontology; KEGG: Kyoto Encyclopedia of Genes and Genomes

\section{Acknowledgments}

The authors are grateful to Dr. X. Ni, USDA-ARS Tifton, Georgia, USA and Dr. Robert L. Stoltz, University of Idaho, for their critical comments on earlier versions of this manuscript and the anonymous referees for their critical comments on this manuscript.

Authors' contributions

$\mathrm{ZQH}, \mathrm{HYZ}$ and DDL designed the experiment. DDL, ZQT, CZ, and DS collected samples. DDL and ZQH performed the RNAseq and analyzed the data. The manuscripts were written and revised by ZQH, DDL, GSZ, SZZ and HYZ. All authors have read and approved the final manuscript.

\section{Funding}

The Project Supported by the National Key Research and Development Program of China (2018YFD0200402), the National Natural Science Foundation of China (Program No. 31401735), and Natural Science Basic Research Plan in Shaanxi Province of China (Program No. 2017JM3030).

\section{Availability of data and materials}

Transcriptome data are available at NCBI with raw sequencing reads deposited in the Sequence Read Archive (accession \# PRJNA490258). We have submitted the sequence of RpSTAT5B to NCBI GeneBank database and the accession number is MK931299.

Ethics approval and consent to participate Not applicable.

\section{Consent for publication} Not applicable.

\section{Competing interests}

The authors declare that they have no competing interests.

\section{Author details}

${ }^{1}$ State Key Laboratory of Crop Stress Biology in Arid Areas, College of Plant Protection, Northwest A\&F University, Yangling, China. ${ }^{2}$ Ministry of Education, Key Laboratory of Crop Heterosis of Shaanxi Province, National Yangling Agricultural Biotechnology and Breeding Center, Yangling Branch of State Wheat Improvement Centre/Wheat Breeding Engineering Research Center, Northwest A\&F University, Yangling, China. 
Received: 20 June 2020 Accepted: 6 September 2020 Published online: 15 September 2020

\section{References}

1. Al-Mousawi AH, Richardson PE, Burton RL. Ultrastructural studies of greenbug (Hemiptera: Aphididae) feeding damage to susceptible and resistant wheat cultivars. Ann Entomol Soc Am. 1983;76:964-71.

2. Song $S$, Tao $Y$, Zhang H, Wu Y. Psathyrostachys huashanica, a potential resource for resistance to barley yellow dwarf virus-gav. Eur J Plant Pathol. 2013;137:217-21.

3. Zhang QF, Guan WN, Ren ZY, Zhu XS. Transmission of barley yellow dwarf virus strains from northwestern China by four aphid species. Plant Dis. 1983; 67:895-9.

4. Nuessly GS, Nagata RT, Burd JD, Hentz MG, Carroll AS, Halbert SE. Biology and biotype determination of greenbug, Schizaphis graminum (hemiptera: aphididae), on seashore paspalum turfgrass (paspalum vaginatum). Environ Entomol. 2008;37:586-91.

5. Hu ZQ, Zhao HY, Thieme T. Comparison of the potential rate of population increase of brown and green color morphs of Sitobion avenae (Homoptera: Aphididae) on barley infected and uninfected with barley yellow dwarf virus. Insect Sci. 2014;21:326-33.

6. Song $S$, Tao Y, Zhao L, Liu P, Wu Y. Isolation and characterization of the complete genome of barley yellow dwarf virus-GAV from wheat in northwestern China. Cereal Res Commun. 2014;1:1-9.

7. Zhou G, Cheng Z, Qian Y, Zhang X, Rochow WF. Serological identification of luteoviruses of small grains in China. Plant Dis. 1984;68:710-3.

8. Liu Y, Wang B, Gyula V, Mónika CK, Wu BL, Wu YH, Wang X. Genomic analysis of the natural population of wheat dwarf virus in wheat from China and Hungary. J Integr Agric. 2012;11:2020-7.

9. Xie J, Wang X, Liu Y, Peng Y, Zhou G. First report of the occurrence of wheat dwarf virus in wheat in China. Plant Dis Int J Appl Plant Pathol. 2007; 91:111.

10. Fereres A, Moreno A. Behavioural aspects influencing plant virus transmission by homopteran insects. Virus Res. 2009;141:158-68.

11. Hohn T. Plant virus transmission from the insect point of view. Proc Nat Acad Sci U S A. 2007;104:17905-6.

12. Colvin J, Omongo CA, Govindappa MR, Stevenson PC, Maruthi MN, Gibson G, Seal SE, Muniyappa V. Host-plant viral infection effects on arthropodvector population growth, development and behaviour: management and epidemiological implications. Adv Virus Res. 2006;67:419-52.

13. Stout MJ, Thaler JS, Thomma BPHJ. Plant-mediated interactions between pathogenic microorganisms and herbivorous arthropods. Annu Rev Entomol. 2006:51:663-89.

14. Baton LA, Garver L, Xi Z, Dimopoulos G. Functional genomics studies on the innate immunity of disease vectors. Insect Sci. 2008;15:15-27.

15. Brault V, Tanguy S, Reinbold C, Le Trionnaire G, Arneodo J, Jaubert-Possamai S, Guernec G, Tagu D. Transcriptomic analysis of intestinal genes following acquisition of pea enation mosaic virus by the pea aphid Acyrthosiphon pisum. J Gen Virol. 2010:91:802-8.

16. Xu Y, Zhou W, Zhou Y, Wu J, Zhou X. Transcriptome and comparative gene expression analysis of Sogatella furcifera (Horváth) in response to southern rice black-streaked dwarf virus. PLoS One. 2012;7:e36238.

17. Schneweis DJ, Whitfield AE, Rotenberg D. Thrips developmental stagespecific transcriptome response to tomato spotted wilt virus during the virus infection cycle in Frankliniella occidentalis, the primary vector. Virology. 2017:500:226-37.

18. Shrestha A, Champagne DE, Culbreath AK, Rotenberg D, Srinivasan R. Transcriptome changes associated with tomato spotted wilt virus infection in various life stages of its thrips vector, Frankliniella fusca (hinds). J Gen Virol. 2017:98:2156-70

19. Xu HX, He XC, Zheng XS, Yang YJ, Zhang JF, Lu ZX. Effects of SRBSDVinfected rice plants on the fitness of vector and non-vector rice planthoppers. J Asia Pac Entomol. 2016;19:707-10.

20. Xu H, He X, Zheng X, Yang Y, Lu Z. Influence of rice black streaked dwarf virus on the ecological fitness of non-vector planthopper Nilaparvata lugens (Hemiptera: Delphacidae). Insect Sci. 2014:21:507-14.

21. Pan H, Chen G, Li F, Wu Q, Wang S, Xie W, Liu B, Xu B, Zhang Y. Tomato spotted wilt virus infection reduces the fitness of a nonvector herbivore on pepper. J Econ Entomol. 2013;106:924-8.
22. Belliure B, Sabelis MW, Janssen A. Vector and virus induce plant responses that benefit a non-vector herbivore. Basic Appl Ecol. 2010;11: 162-9.

23. Hoffmann JA. Innate immunity of insects. Curr Opin Immunol. 1995;7:4-10.

24. Badillovargas IE, Rotenberg D, Schneweis DJ, Hiromasa Y, Tomich JM, Whitfield AE. Proteomic analysis of Frankliniella occidentalis and differentially expressed proteins in response to tomato spotted wilt virus infection. J Virol. 2012;86:8793.

25. Medeiros RB, Resende RDO, De Avila AC. The plant virus tomato spotted wilt tospovirus activates the immune system of its main insect vector, Frankliniella occidentalis. J Virol. 2004;78:4976-82.

26. Filho FMA, Stavisky J, Reitz SR, Deom CM, Sherwood JL. Midgut infection by tomato spotted wilt virus and vector incompetence of Frankliniella tritici. J Appl Entomol. 2005;129:548-50.

27. Schmid-Hempel P. Evolutionary ecology of insect immune defenses. Annu Rev Entomol. 2005;50:529-51

28. Tang L, Liang J, Zhan Z, Xiang Z, He N. Identification of the chitin-binding proteins from the larval proteins of silkworm, Bombyx mori. Insect Biochem Mol Biol. 2010;40:228-34

29. Gallot A, Rispe C, Leterme N, Gauthier JP, Jaubert-Possamai S, Tagu D. Cuticular proteins and seasonal photoperiodism in aphids. Insect Biochem Mol Biol. 2010:40:235e240.

30. Willis JH. Structural cuticular proteins from arthropods: annotation, nomenclature, and sequence characteristics in the genomics era. Insect Biochem Mol Biol. 2010:40:189-204

31. McTaggart SJ, Hannah T, Bridgett S, Garbutt JS, Kaur G, Boots M. Novel insights into the insect trancriptome response to a natural DNA virus. BMC Genomics. 2015;16:310.

32. Kato N, Mueller CR, Fuchs JF, McElroy K, Wessely V, Higgs S, Christensen BM. Evaluation of the function of a type I peritrophic matrix as a physical barrier for midgut epithelium invasion by mosquito-borne pathogens in Aedes aegypti. Vector-Borne Zoonotic Dis. 2008:8:701-12.

33. Levy SM, Falleiros AMF, Moscardi F, Gregorio EA. The role of peritrophic membrane in the resistance of Anticarsia gemmatalis larvae (Lepidoptera: Noctuidae) during the infection by its nucleopolyhedrovirus (AgMNPV). Arthropod Struct Dev. 2011:40:429-34.

34. Wang L, Tang N, Gao X, Guo D, Chang Z, Fu Y, Akinyemi IA, Wu Q. Understanding the immune system architecture and transcriptome responses to southern rice black-streaked dwarf virus in Sogatella furcifera. Sci Rep. 2016;6:36254

35. Steinert S, Levashina EA. Intracellular immune responses of dipteran insects. Immunol Rev. 2011;240:129-40.

36. Radtke K, Döhner K, Sodeik B. Viral interactions with the cytoskeleton: a hitchhiker's guide to the cell. Cell Microbiol. 2006:8:387-400.

37. Simpson-Holley M, Ellis D, Fisher D, Elton D, Mccauley J, Digard P. A functional link between the actin cytoskeleton and lipid rafts during budding of filamentous influenza virions. Virology. 2002:301:212-25.

38. Taylor MP, Koyuncu OO, Enquist LW. Subversion of the actin cytoskeleton during viral infection. Nat Rev Microbiol. 2011:9:427-39.

39. Laporte C, Vetter G, Loudes AM, Robinson DG, Ritzenthaler C. Involvement of the secretory pathway and the cytoskeleton in intracellular targeting and tubule assembly of grapevine fanleaf virus movement protein in tobacco BY-2 cells. Plant Cell. 2003:15:2058-75.

40. Harries PA, Schoelz JE, Nelson RS. Intracellular transport of viruses and their components: utilizing the cytoskeleton and membrane highways. Mol Plant-Microbe Interact. 2010;23:1381-93.

41. Schoelz JE, Harries PA, Nelson RS. Intracellular transport of plant viruses: finding the door out of the cell. Mol Plant. 2011;4:813-31.

42. Cassone BJ, Wijeratne S, Michel AP, Stewart LR, Chen Y, Yan P, Redinbaugh MG. Virus-independent and common transcriptome responses of leafhopper vectors feeding on maize infected with semipersistently and persistent propagatively transmitted viruses. BMC Genomics. 2014;15:133.

43. Lemaitre B, Hoffmann J. The host defense of Drosophila melanogaster. Annu Rev Immunol. 2007;25:697-743.

44. Gonen H, Bercovich B, Orian A, Carrano A, Takizawa C, Yamanaka K, Pagano M, Iwai K, Ciechanover A. Identification of the ubiquitin carrier proteins, E2s, involved in signal-induced conjugation and subsequent degradation of IKBa. J Biol Chem. 1999;274:14823-30.

45. Dubrez-Daloz L, Dupoux A Cartie J. IAPs: more than just inhibitors of apoptosis proteins. Cell Cycle. 2008;7:1036-46. 
46. Kadaré G, Toutant M, Formstecher E, Corvol JC, Carnaud M, Boutterin MC, Girault JA. PIAS1-mediated sumoylation of focal adhesion kinase activates its autophosphorylation. J Biol Chem. 2003;278:47434-40.

47. Kubo $\mathrm{Y}$, Hayashi $\mathrm{H}$, Matsuyama $\mathrm{T}$, Sato $\mathrm{H}$, Yamamoto N. Retrovirus entry by endocytosis and cathepsin proteases. Adv Virol. 2012;640894:14.

48. Sim S, Ramirez JL, Dimopoulos G. Dengue virus infection of the Aedes aegypti salivary gland and chemosensory apparatus induces genes that modulate infection and blood-feeding behavior. PLoS Pathog. 2012;8: e1002631.

49. Pinheiro PV, Ghanim M, Matsuda Alexander MM, Rebelo AR, Santos RS, Orsburn BC, Gray S, Cilia M. Host plants indirectly influence plant virus transmission by altering gut cysteine protease activity of aphid vectors. Mol Cell Proteomics. 2017;16(4 Suppl 1):S230.

50. Dostert C, Jouanguy E, Irving P, Troxler L, Galiana-Arnoux D, Hetru C, Hoffmann JA, Imler JL. The Jak-STAT signaling pathway is required but not sufficient for the antiviral response of drosophila. Nat Immunol. 2005;6:946-53.

51. Hedges LM, Johnson KN. Induction of host defence responses by Drosophila C virus. J Gen Virol. 2008:89:1497-501.

52. Kingsolver MB, Huang Z, Hardy RW. Insect antiviral innate immunity: pathways, effectors, and connections. J Mol Biol. 2013;425:4921-36.

53. Zhang Z, Zhang P, Li W, Zhang J, Huang F, Yang J, Bei Y, Lu Y. De novo transcriptome sequencing in Frankliniella occidentalis to identify genes involved in plant virus transmission and insecticide resistance. Genomics. 2013;101:296-305

54. Hou S, Zheng Z, Chen X, Perrimon N. The JAK/STAT pathway review in model organisms: emerging roles in cell movement. Dev Cell. 2002;3: 765-78.

55. Kaneko T, Yano T, Aggarwal K, Lim JH, Ueda K, Oshima Y, Peach C, ErturkHasdemir D, Goldman WE, Oh B, Kurata S, Silverman N. PGRP-LC and PGRPLE have essential yet distinct functions in the drosophila immune response to monomeric DAP-type peptidoglycan. Nat Immunol. 2006;7:715-23.

56. Liu B, Liao J, Rao X, Kushner SA, Chung CD, Chang DD, Shuai K. Inhibition of Stat1-mediated gene activation by PIAS1. Proc Natl Acad Sci. 1998;95: 10626-31.

57. Rawlings JS, Rosler KM, Harrison DA. The JAKJSTAT signaling pathway. J Cell Sci. 2004:117:1281-3.

58. Boucheron CA. Single amino acid in the DNA binding regions of STAT5A and STAT5B confers distinct DNA binding specificities. J Biol Chem. 1998; 273:33936-41

59. Zhang T, Kee WH, Seow KT, Fung W, Cao X. The coiled-coil domain of STAT3 is essential for its SH2 domain-mediated receptor binding and subsequent activation induced by epidermal growth factor and interleukin6. Mol Cell Biol. 2000;20:7132-9.

60. Wakao H, Gouilleux F, Groner B. Mammary gland factor (MGF) is a novel member of the cytokine regulated transcription factor gene family and confers the prolactin response. EMBO J. 1995;14:854-5.

61. Shuai K, Horvath CM, Huang LHT, Qureshi SA, Cowburn D, Darnell JE. Interferon activation of the transcription factor stat91 involves dimerization through sh2-phosphotyrosyl peptide interactions. Cell. 1994;76:821-8.

62. Kisseleva T, Bhattacharya S, Braunstein J, Schindler CW. Signaling through the jak/stat pathway, recent advances and future challenges. Gene (Amsterdam) 2002;285:0-24.

63. Hu Z, Zhao H, Thieme T. Modification of non-vector aphid feeding behavior on virus-infected host plant. J Insect Sci. 2013;13:1-11.

64. Grabherr MG, Haas BJ, Yassour M, Levin JZ, Thompson DA, Amit I, Adiconis X, Fan L, Raychowdhury R, Zeng Q, Chen Z, Mauceli E, Hacohen N, Gnirke A, Rhind N, di Palma F, Birren BW, Nusbaum C, Lindblad-Toh K, Friedman N, Regev A. Full length transcriptome assembly from RNA Seq data without a reference genome. Nat Biotechnol Italic. 2011;29:644-52.

\section{Publisher's Note}

Springer Nature remains neutral with regard to jurisdictional claims in published maps and institutional affiliations.

Ready to submit your research? Choose BMC and benefit from:

- fast, convenient online submission

- thorough peer review by experienced researchers in your field

- rapid publication on acceptance

- support for research data, including large and complex data types

- gold Open Access which fosters wider collaboration and increased citations

- maximum visibility for your research: over $100 \mathrm{M}$ website views per year

At BMC, research is always in progress.

Learn more biomedcentral.com/submissions 